Energy Division

\title{
Will Duct Tape and Plastic Really Work? Issues Related To Expedient Shelter-In-Place
}

\author{
John H. Sorensen \\ Barbara M. Vogt
}

Date Published-August 2001

Prepared for the

Federal Emergency Management Agency

Chemical Stockpile Emergency Preparedness Program

\author{
Prepared by \\ OAK RIDGE NATIONAL LABORATORY \\ Oak Ridge, Tennessee 37831-6285 \\ managed by \\ UT-BATTELLE, LLC \\ for the \\ U.S. DEPARTMENT OF ENERGY \\ under contract DE-AC05-00OR22725
}




\section{CONTENTS}

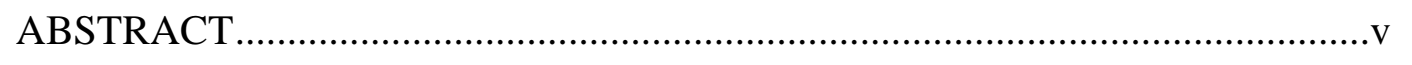

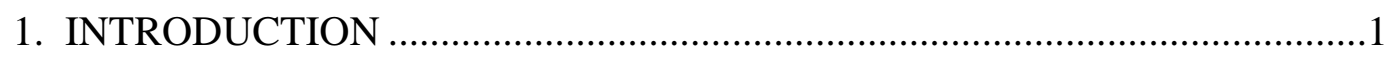

2. EXPEDIENT SHELTERING ..............................................................

3. WHY WERE THESE MATERIALS CHOSEN? .........................................

3.1 DUCT TAPE PERMEABILITY ....................................................2

3.2 PLASTIC SHEETING PERMEABILITY …..................................... 3

4. HOW HAVE THEY PERFORMED IN TESTS OR REAL EVENTS? ............3

5. TIMING OF EXPEDIENT SHELTER ..............................................

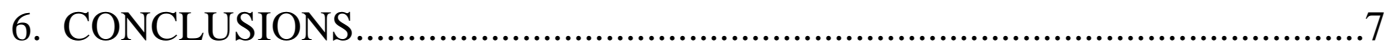

7. ACKNOWLEDGMENTS ..................................................................

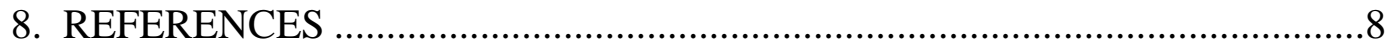




\begin{abstract}
Expedient sheltering involves the use of common materials to enhance the safety of a room inside a building against the impacts of a chemical plume. The central premise behind taping and sealing with duct tape and plastic is to reduce airflow into a room. This paper reviews issues associated with the use of expedient sheltering materials and the effectiveness of this strategy.

Expedient sheltering provides additional protection to people sheltering in place beyond that provided by the house and by a safe room without expedient measures. The materials chosen for taping and sealing — duct tape and plastic_-are appropriate because they effectively reduce infiltration and the materials should withstand a vapor challenge. Taping is essential to reduce air infiltration. Plastic sheeting is not a critical element for reducing air infiltration, but it makes sealing off large windows easier.
\end{abstract}




\section{INTRODUCTION}

Sheltering is a protective action strategy developed to protect people from chemical vapors and aerosols. The Chemical Stockpile Emergency Preparedness Program (CSEPP) Planning Guidance (1996) identified four different types of sheltering:

- normal sheltering,

- enhanced sheltering,

- expedient sheltering, and

- pressurized sheltering.

Although pressurized shelters provide the greatest protection against a chemical plume, their expense and intrusiveness make them impractical for widespread use. Expedient sheltering provides more protection than normal sheltering, which only involves going indoors and closing up the house and shutting off HVAC systems. This paper reviews issues associated with the use of expedient sheltering materials and the effectiveness of this strategy.

\section{EXPEDIENT SHELTERING}

Expedient sheltering involves the use of common materials to enhance the safety of a room inside a building against the impacts of a chemical plume. The central premise behind taping and sealing with duct tape and plastic is to reduce airflow into a room. Vapors penetrate into a room through cracks and openings in the walls, floors and ceilings, around doors and windows, and through openings for ducts, light fixtures, fans, pipes, electrical outlets, chimneys, door handles, and locks. The goal of taping and sealing is to significantly reduce infiltration at these points.

Expedient sheltering was suggested by NATO (1983) using the term "ad-hoc shelter" to protect civilian populations from chemical warfare agent exposure. The concept was to use plastic sheeting to seal off a room by fashioning a simple airlock at the entrance to the room and sealing off doors, windows or louvered vents. The NATO guidelines also stressed the need for rapid exit from the ad-hoc shelter once the plume had passed to avoid further exposure (NATO 1983, p. 143).

This strategy was further developed by the Israeli Civil Defense in the mid-1980s to protect the public against a chemical weapons attack (Yeshua 1990). The tape and seal strategy was in place when the Gulf War occurred in 1991 and received considerable media attention. The Israeli strategy was to have citizens prepare a "safe room" in their house or apartment with the use of weatherization techniques to permanently reduce infiltration. Citizens were also instructed to take expedient measures, such as sealing 
doors and windows with plastic sheets, in the event of a chemical weapons attack. The use of plastic over a window was developed to reduce air infiltration and to provide a vapor barrier in the event of glass breakage from bomb explosions. A modification of the Israeli strategy was proposed for use in CSEPP (Sorensen 1988; Rogers et al. 1990).

Although vapors, aerosols, and liquids cannot permeate glass windows or door panes, the amount of possible air filtration through the seals of the panes into frames could be significant, especially if frames are wood or other substance subject to expansion and contraction. To adequately seal the frames with tape could be difficult or impractical. For this reason, it has been suggested that pieces of heavy plastic sheeting larger than the window be used to cover the entire window, including the inside framing, and sealed in place with duct or other appropriate adhesive tape applied to the surrounding wall.

Another possible strategy would be to use shrink-wrap plastic often used in weatherization efforts in older houses. Shrink-wrap commonly comes in a 6 mil (0.006-in.) thickness and is adhered around the frame with double-faced tape and then heated with a hair dryer to achieve a tight fit. This would likely be more expensive than plastic sheeting and would require greater time and effort to install. Because double-faced tape has not been challenged with chemical warfare agents, another option is to use duct tape to adhere shrink-wrap to the walls. Currently, we do not recommend using shrinkwrap plastics because of the lack of information on its suitability and performance.

\section{WHY WERE THESE MATERIALS CHOSEN?}

Duct tape and plastic sheeting (polyethylene) were chosen because of their ability to effectively reduce infiltration and for their resistance to permeation from chemical warfare agents.

\subsection{DUCT TAPE PERMEABILITY}

Work on the effectiveness of expedient protection against chemical warfare agent simulants was conducted as part of a study on chemical protective clothing materials (Pal et al. 1993). Materials included a variety of chemical resistant fabrics and duct tape of 10 mil (0.01-in.) thickness. The materials were subject to liquid challenges by the simulants DIMP (a GB simulant), DMMP (a VX simulant), MAL (an organoposphorous pesticide), and DBS (a mustard simulant). The authors note that simulants should behave similarly to live agents in permeating the materials; they also note that this should be confirmed with the unitary agents. The study concluded that "duct tape exhibits reasonable resistance to permeation by the 4 simulants, although its resistance to DIMP $(210 \mathrm{~min})$ and DMMP (210 min) is not as good as its resistance to MAL ( $>24 \mathrm{~h})$ and DBS $(>7 \mathrm{~h})$. Due to its wide availability, duct tape appears to be a useful expedient material to provide at least a temporary seal against permeation by the agents" (Pal et al. 1993, p. 140). 


\subsection{PLASTIC SHEETING PERMEABILITY}

Tests of the permeability of plastic sheeting (polyethylene) challenged with live chemical warfare agents were conducted at the Chemical Defense Establishment in Porton Down, England in 1970 (NATO 1983, p. 133). Agents tested included H and VX, but not GB. Four types of polyethylene of varying thickness were tested: $2.5,4,10$ and 20 mil $(0.0025,0.004 \mathrm{in} ., 0.01 \mathrm{in}$., and $0.02 \mathrm{in}$.). The results of these tests are shown in Table 1.

Table 1: Permeability of plastic sheeting to liquid agent

\begin{tabular}{ccc}
\hline & \multicolumn{2}{c}{ Breakthrough time (h) } \\
\cline { 2 - 3 } Thickness & VX & H \\
\hline 0.0025 & 3 & 0.3 \\
0.004 & 7 & 0.4 \\
0.01 & 30 & 2 \\
0.02 & 48 & 7 \\
\hline
\end{tabular}

Source: NATO 1983, p. 136.

The data shows that at thickness of 10 mil or greater, the plastic sheeting provided a good barrier for withstanding liquid agent challenges, offering better protection against VX than for $\mathrm{H}$. Because the greatest challenge is from a liquid agent, the time to permeate the sheeting will be longer for aerosols and still longer for vapors, but the exact relationship is unknown due to a lack of test data.

In Fig. 1 we plot the data in Table 1 to determine the nature of the relationship between thickness and breakthrough time. The data suggest a somewhat linear relationship, thus allowing some interpolation for various thickness of plastic sheeting. For reference, commercially available sheeting is typically sold at $0.7,1,1.2,1.5,2, .2 .5,3,4,6$, and 10 mil. although thicker material is available (up to 100 mil). Plastic painter drop cloths are sold between 0.5 and 2 mil.

\section{HOW HAVE THEY PERFORMED IN TESTS OR REAL EVENTS?}

Although the "safe room" strategy was used in the many scud missile attacks against Israel in the Gulf War, no chemical agents were released during these attacks. Sheltering has been recommended as a protective action in several chemical releases in the United States and Canada. Some anecdotal information exists about sheltering effectiveness in those events, but no empirical studies of actual effectiveness in a real event have been conducted. Such data would be extremely difficult to capture. Two sets of experiments have been conducted on the effectiveness of in-place sheltering (Rogers et al. 1990; Blewett et al. 1996). 


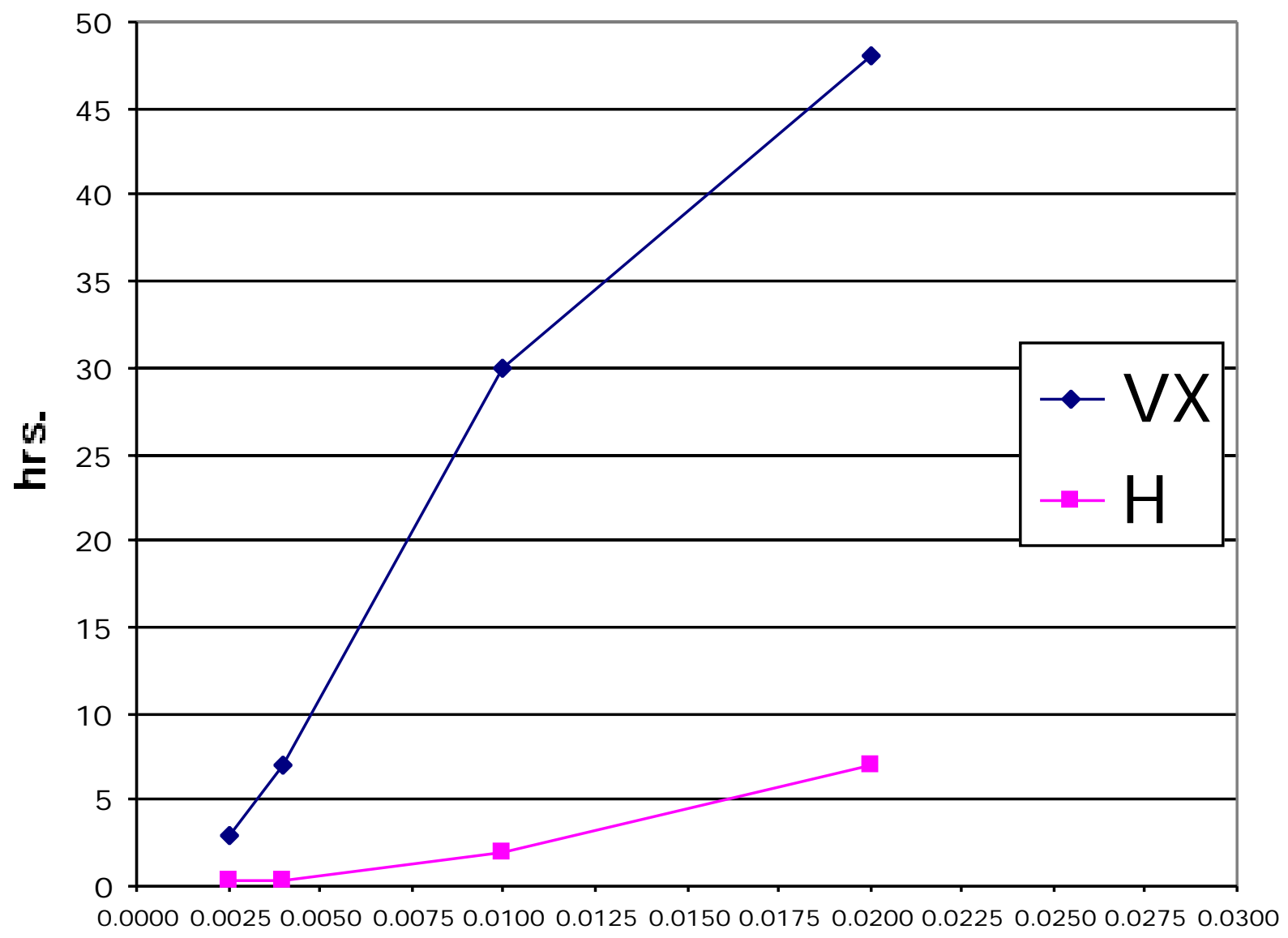

thickness

Fig. 1. Breakthrough as a function of the thickness of plastic sheeting.

The results of the two sets of experiments or trials using tracer gas methods provide some insight into the effectiveness of expedient sheltering. These trials were conducted in the vicinity of Oak Ridge, TN., in the late 1980s and Edgewood, MD in the mid 1990's. The Oak Ridge tests involved 12 single-family homes. The trials measured the air exchange for the whole house, the expedient room (mainly bathrooms) with a towel against the door, and the bathroom fully taped and sealed by a household member. Materials used included duct tape, flexible insulation cord, and plastic sheeting. In each test, subjects were given written instructions and checklists, but were left to make the decision how to seal the room.

Infiltration or air exchange is measured by the number of air changes per hour (ach). The average air exchange rate for the houses tested in the Oak Ridge trials was $0.45 \mathrm{ach}$. The bathrooms with a towel averaged only $0.94 \mathrm{ach}$. The fully sealed bathrooms averaged 
0.33 ach, a reduction of 0.61 ach or $65 \%(0.61 / 0.94)$. One factor not assessed in the study was the air exchanged between the sealed room and the whole house versus the sealed room and the outside. If one assumes that the air exchanged by the room is mostly with the rest of the house, an added protection factor would be achieved because the contaminated air concentrations outside the house are reduced by mixing with air in the whole house and then reduced again in the expedient room. If it is assumed that most of the exchange is between the room and the outside, little added protection beyond that provided by the room would be achieved.

The tests in Edgewood, Maryland, involved 10 residential buildings and 2 mobile homes. Three types of rooms were tested: bathrooms with windows, windowless bathrooms, and walk-in closets. The expedient measures were applied by technicians, and the doors were taped from the outside of the room. A total of 36 trials were performed using different configurations of protection. The results (Table 2) show the air exchange rate for the whole house and for the room in which the expedient measure(s) was applied. The most aggressive strategy (Method 2) proved to be fairly effective, reducing average air exchange rates to between 0.15 and 0.21 ach.

Table 2: Results of Edgewood trials

\begin{tabular}{lcc}
\hline \multicolumn{1}{c}{ Room and method } & $\begin{array}{c}\text { Average } \\
\text { house ach }\end{array}$ & $\begin{array}{c}\text { Average } \\
\text { room ach }\end{array}$ \\
\hline Bathroom—no expedient measures & 0.29 & 0.27 \\
Method 1: Bathroom—wet towel and taped vent & 0.28 & 0.23 \\
$\begin{array}{l}\text { Method 2: Bathroom—door taped, plastic sheet on } \\
\quad \text { window, wet towel and taped vent }\end{array}$ & 0.32 & 0.21 \\
$\begin{array}{l}\text { Windowless bathroom—-no expedient measures } \\
\text { Method 1: Windowless bathroom—wet towel and }\end{array}$ & 0.37 & 0.29 \\
$\quad$ taped vent & 0.33 & 0.29 \\
$\begin{array}{l}\text { Method 2: Windowless bathroom—door taped, wet } \\
\quad \text { towel and taped vent }\end{array}$ & 0.34 & 0.15 \\
$\begin{array}{l}\text { Walk in closet—no expedient measures } \\
\text { Method 1: Walk in closet—wet towel and taped vent }\end{array}$ & 0.39 & 0.44 \\
$\begin{array}{l}\text { Method 2: Walk in closet—door taped, wet towel } \\
\text { and taped vent }\end{array}$ & 0.21 & 0.30 \\
\hline
\end{tabular}

A good way of examining the numbers in the table is to compare the baseline case (door closed with no expedient protection) to the case with the greatest amount of expedient protection (Method 2). For the bathroom, the ach dropped from 0.27 to 0.21 (22\%). For the windowless bathroom, the ach dropped from 0.29 to 0.15 (48\%). For the closet, the ach dropped from 0.28 to $0.15(46 \%)$.

The results of the two studies are consistent. Both studies showed a reduction of average air exchange rates from expedient protective measures. In some of the specific rooms tested such measures substantially reduced air infiltration into the sealed room when compared to the unsealed room. Infiltration was reduced in one trial by $90 \%$ in the 
Oak Ridge study and by $57 \%$ in Edgewood study. In addition, fairly low air exchanges were achieved in some of the specific expedient room trials ( 0.11 ach in both studies). The effectiveness of individual trials varied. In the Oak Ridge study, the lowest reduction was $13 \%$ and highest air exchange rate was 0.58 ach. In the Edgewood study, the highest air exchange rate for the most aggressive strategy (Method 2) was 0.31 ach. The greater variability in the Oak Ridge data likely results from the variability in the way individuals implemented the taping and sealing, which was more uniform in the Edgewood study because taping was done in a consistent manner by a skilled technician.

\section{TIMING OF EXPEDIENT SHELTER}

In the ORNL study (Rogers et al. 1990), the time to implement the expedient protection was recorded. Overall times ranged between 3 and 44 min in total, with a mean of 19.8 min. The time to close up the house was relatively short, with a mean of $3.2 \mathrm{~min}$ with a range of 1 to $6 \mathrm{~min}$. Times to tape and seal ranged between 2.3 and $38.6 \mathrm{~min}$, with a mean of $16.7 \mathrm{~min}$. These data are shown in Fig. 2.

Time To Implement Expedient Shelter

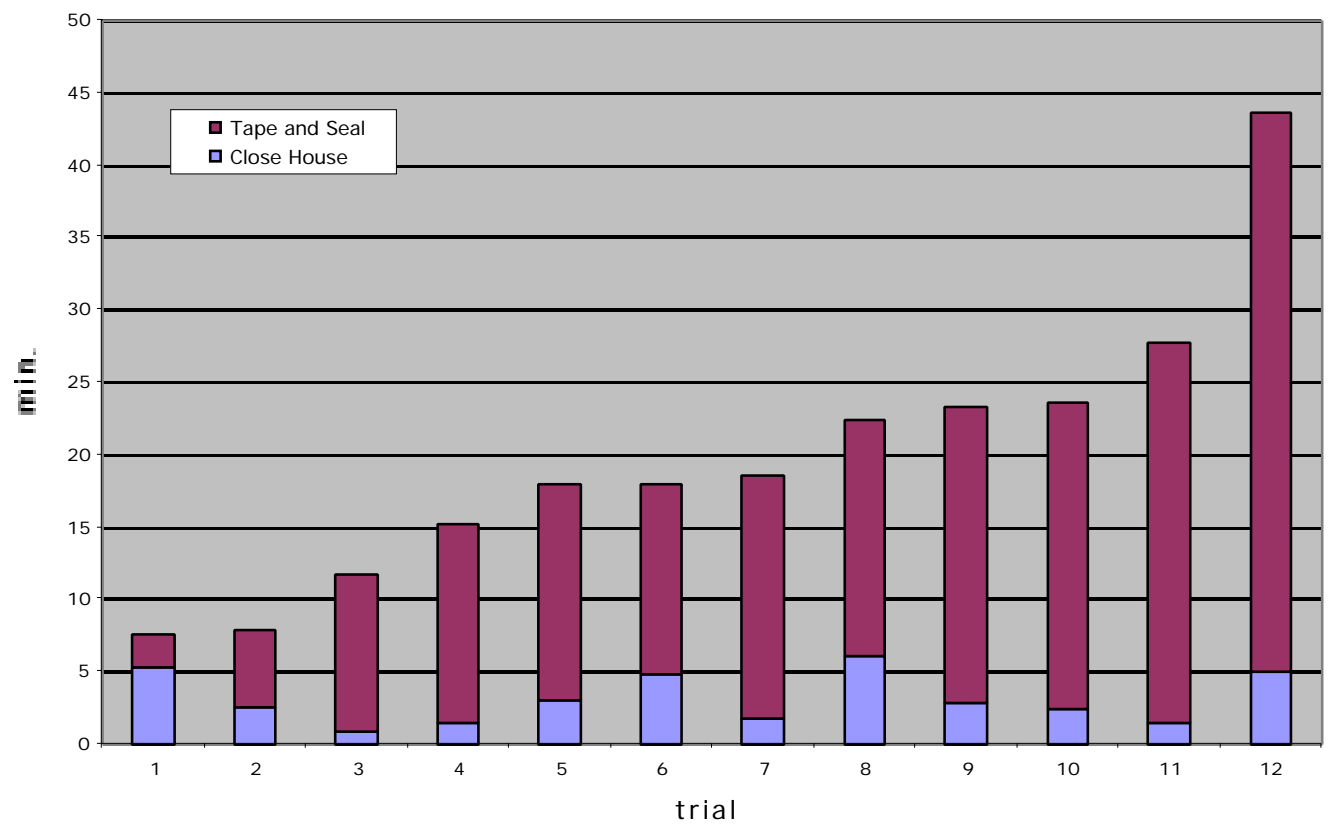

Fig. 2: Expedient shelter trial times. 


\section{CONCLUSIONS}

Expedient sheltering provides additional protection to people sheltering in place beyond that provided by the house and by a safe room without expedient measures. The materials chosen, such as duct tape and plastic, are appropriate because they effectively reduce infiltration and the materials should withstand a vapor challenge. Taping is essential to reduce air infiltration. Plastic sheeting is not a critical element for reducing air infiltration, but it makes sealing off large windows easier. Shrink-wrap window insulation kits may offer a good alternative for plastic sheeting.

The critical part of the problem is sealing off all routes of air infiltration. The weakest link is the edges of the seals and not the materials used. Inadequate taping and sealing will reduce the effectiveness of expedient sheltering. Overall the choice of the room, the baseline tightness of the room, and human variability in implementing expedient protection will be the major factors in determining the effectiveness of expedient shelter. The latter factor raises issues for the elderly, mobility impaired or handicapped persons, who may lack the physical ability or resources to tape and seal.

\section{ACKNOWLEDGMENTS}

The authors thank Marianne Rutishauser, Tooele County, Utah and Barry Shumpert, University of Tennessee for their helpful reviews of this paper. 


\section{REFERENCES}

Blewett, W. K., D. W. Reeves, V. J. Arca, D. P. Fatkin, and B. D. Cannon 1996. Expedient Sheltering in Place: An Evaluation for the Chemical Stockpile Emergency Preparedness Program, ERDEC-TR-336, Edgewood Research, Development, and Engineering Center, Aberdeen Proving Ground, Md.

NATO Civil Defense Committee 1983. NATO Handbook on Standards and Rules for the Protection of the Civil Population Against Chemical Toxic Agents, AC/23-D/680, 2nd rev.

Pal, T., G.Griffin, G. Miller, A. Watson, M. Doherty, and T. Vo-Dinh. 1993. "Permeation Measurements of Chemical Agent Simulants Through Protective Clothing Materials," J. Haz. Mat. 33:123-141.

Rogers, G. O., A. P. Watson, J. H. Sorensen, R. D. Sharp, and S. A. Carnes. 1990. Evaluating Protective Actions for Chemical Agent Emergencies, ORNL-6615, Oak Ridge National Laboratory, Oak Ridge, Tenn.

Sorensen, J. H. 1988. Evaluation of Warning and Protective Actions Implementation Times for Chemical Weapons Accidents, ORNL/TM-10437, Oak Ridge National Laboratory, Oak Ridge, Tenn.

Yeshua, I. 1990. Chemical Warfare: A Family Defense Manual, Centre for Educational Technology, Ramat Aviv, Israel.

U.S. Department of the Army and Federal Emergency Management Agency. 1996. Planning Guidance for the Chemical Stockpile Emergency Preparedness Program, Washington, D.C. 


\section{INTERNAL DISTRIBUTION}

1. W. G. Craddick

2. T. R. Curlee

3. P. S. Hu

4. C. I. Moser

5. R. B. Shelton

6. J. H. Sorensen

7. B. M. Vogt

8. Central Research Library

9. Document Reference Section

10. Laboratory Records (RC)

\section{EXTERNAL DISTRIBUTION}

11. Dr. Lilia A. Abron, President, PEER Consultants, P.C., 1460 Gulf Blvd., Apt. 1103, Clearwater, Florida 33767.

12. Dr. Douglas Bauer, Executive Director, Commission on Engineering and Technical Systems, National Research Council, Harris 280, 2001 Wisconsin Avenue, NW, Washington, DC 20007.

13. Dr. Susan L. Cutter, Professor and Chair, Director, Hazards Research Lab, Department of Geography, University of South Carolina, Columbia, SC 29208.

14. Dr. Stephen G. Hildebrand, Director, Environmental Sciences Division, Oak Ridge National Laboratory, P.O. Box 2008, Oak Ridge, TN 37831-6037.

15. Mr. P. Richard Rittelmann, FAIA, Executive Vice President, Chairperson Burt Hill Kosar Rittelmann Associates, 400 Morgan Center, Butler, PA 16001-5977.

16. Dr. C. Michael Walton, Ernest H. Cockrell Centennial Chair in Engineering, Department of Civil Engineering, University of Texas at Austin, Austin, TX 787121076. 